\title{
LOWER POLE HYDRONEPHROSIS SIMULATING \\ NEOPLASM IN DUPLICATED KIDNEY
}

\author{
STEPHEN A. KOFF, M.D. \\ From the Section of Urology, Department of Surgery, \\ University of Michigan Medical Center, \\ Ann Arbor, Michigan
}

\begin{abstract}
An interesting case of nonobstructive lower pole hydronephrosis associated with reflux and simulating a neoplasm is presented and discussed.
\end{abstract}

Advanced hydronephrosis localized to one portion of a duplicated kidney in adults may simulate a renal neoplasm on intravenous pyelogram. Upper pole hydronephrosis is a well-described clinical entity and is prominent in the differential diagnosis of renal mass lesions. Although lower pole hydronephrosis occurs more commonly, it has only rarely been reported to cause confusion in the diagnosis of renal masses. An interesting case of lower pole hydronephrosis simulating a neoplasm is presented and discussed.

\section{Case Report}

A fifty-two-year-old white male was admitted for evaluation of urinary infection and hematuria. Irritative and obstructive symptoms associated with urinary incontinence were present for two years. Physical examination was normal; the prostate was of normal size and consistency. Laboratory data were as follows: blood urea nitrogen $17 \mathrm{mg}$. and creatinine $0.9 \mathrm{mg}$. per $100 \mathrm{mI}$.; urinalysis revealed many white blood cells, red blood cells, and bacteria. Cystometrogram demonstrated an uninhibited neurogenic bladder. Cystoscopy disclosed a heavily trabeculated bladder with diverticula, saccules, and vesical outlet obstruction. Cystitis and trabeculation precluded identification of the ureteral orifices. Intravenous pyelography (Fig. 1) and nephrotomography (Fig. 2A) revealed an abnormal left kidney with calyceal distortion suggesting a lower pole mass. Selective renal angiography (Fig. 2B) disclosed a duplicated collecting system

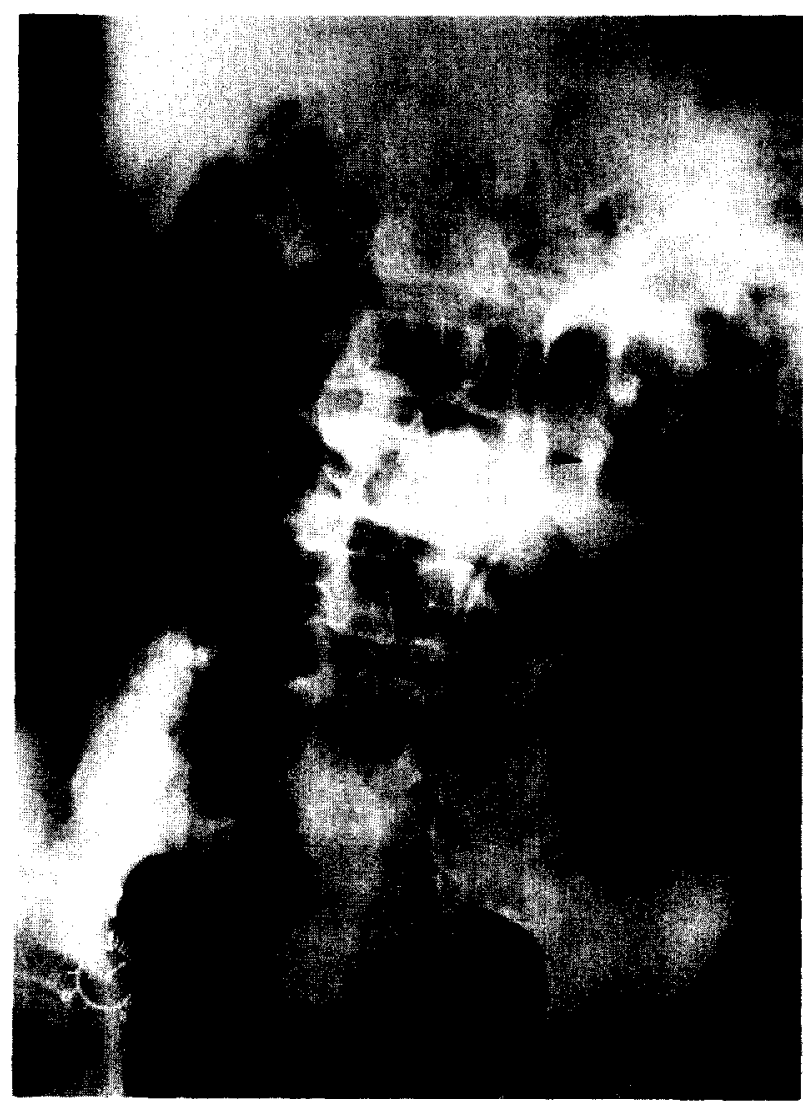

FIGURE 1. Intravenous pyelogram demonstrates irregular collections of contrast in lower pole of left kidney (arrows).

with atrophic pyelonephritis. Delayed filming after angiography (Fig. 3A) demonstrated complete duplication of the left ureter and pelvis with lower pole hydronephrosis. 

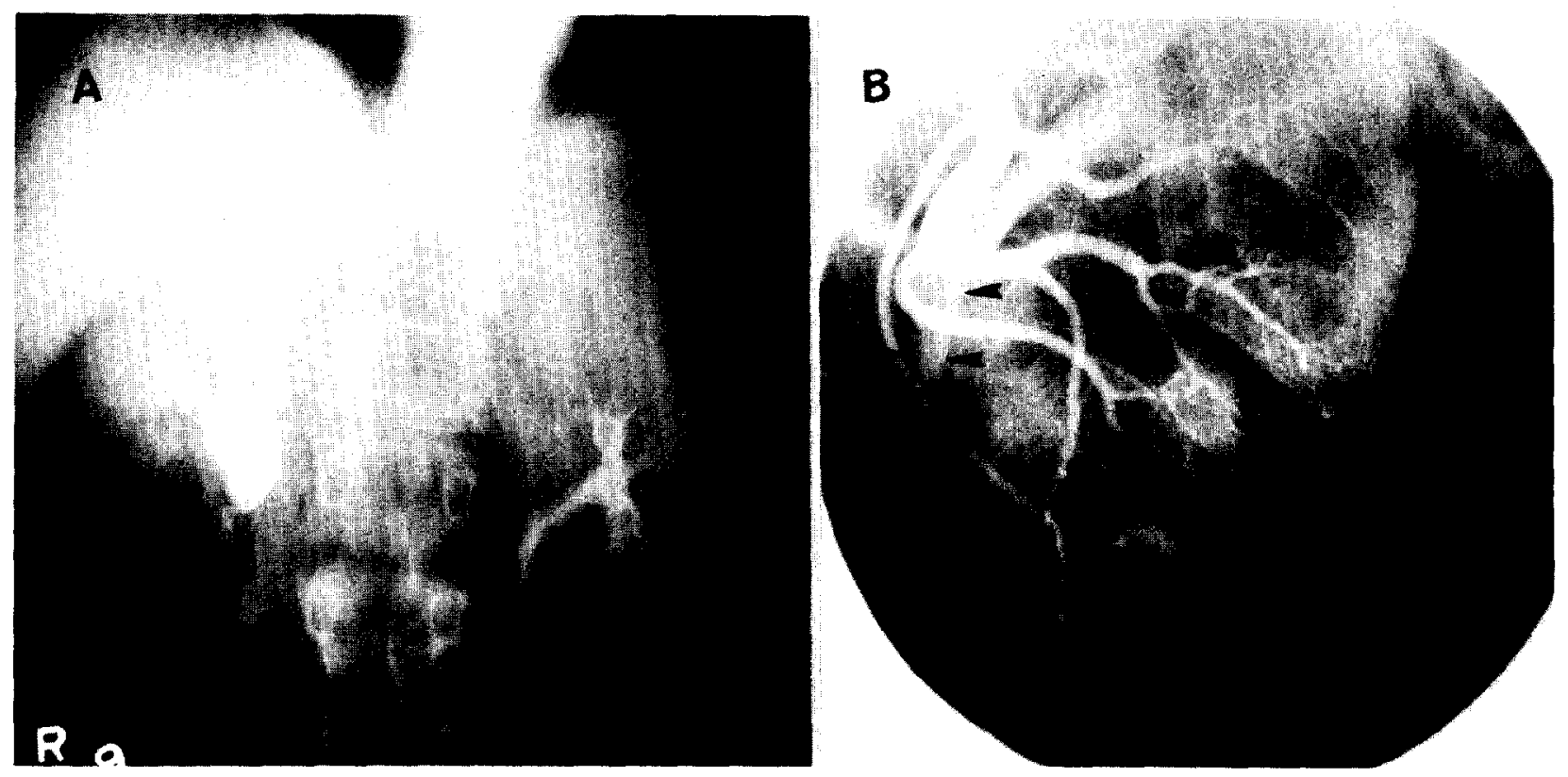

FIGURE 2. (A) Nephrotomogram shows mass lesion in lower pole of left kidney (arrows); calyceal distortion present. (B) Magnified selective left renal arteriogram shows decreased vascular supply to hydronephrotic pyelonephritic lower pole; no neoplasm present. Duplicated collecting systems indicated (large arrows, lower system; small arrows, upper system).

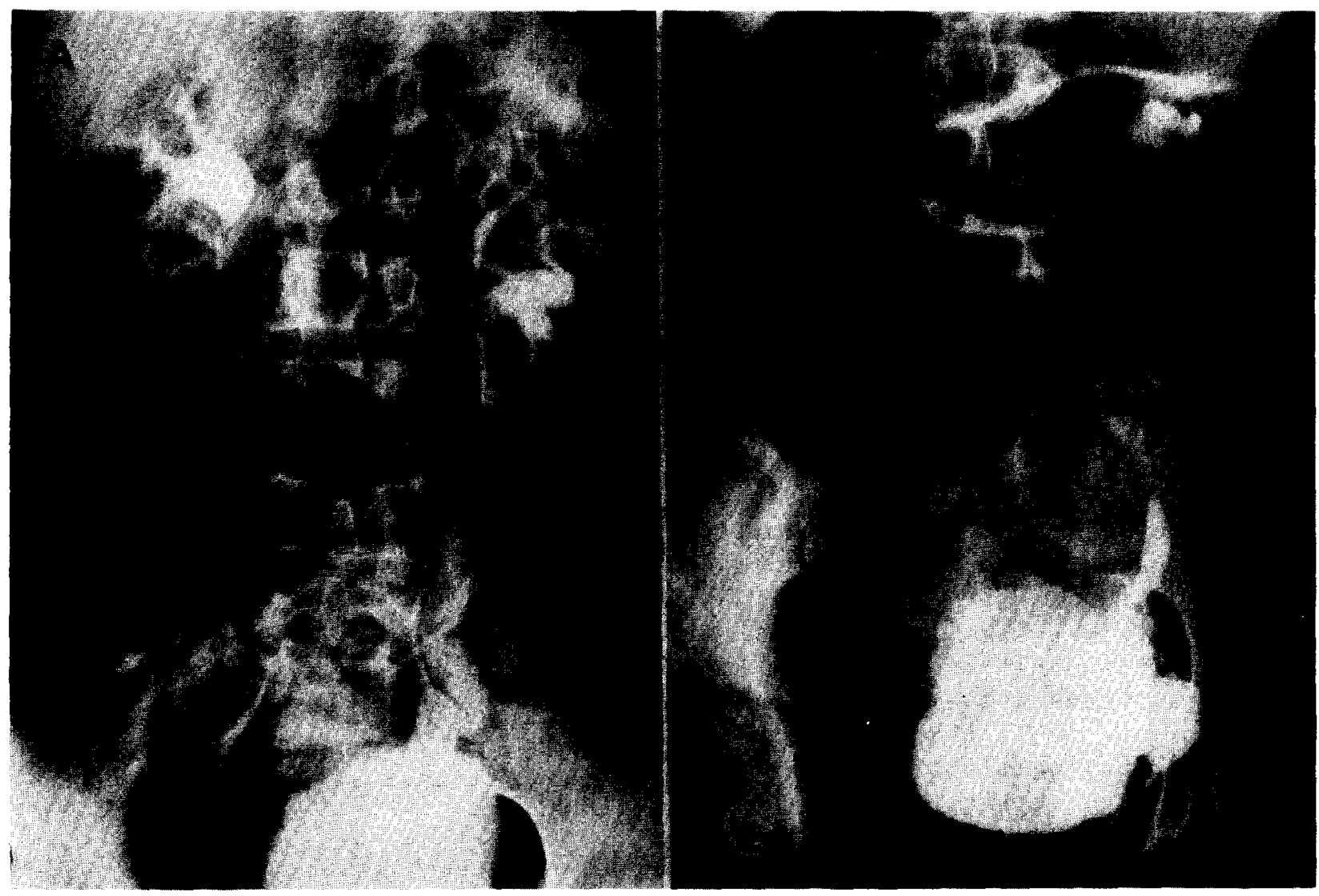

FIGURE 3. (A) Delayed film following renal angiography shows complete duplication of collecting system on left with lower segment hydroureteronephrosis. (B) Cystogram taken two months postoperatively shows reflux into lower left renal segment with improvement in hydronephrosis. Heavily trabeculated bladder with diverticula noted. 
The patient underwent transurethral resection of the prostate and was treated with antibiotics and anticholinergic medication. Two months postoperatively the urine was uninfected, and the cystogram showed improvement of the hydronephrosis (Fig. 3B).

\section{Comment}

Duplication of the ureters is a common anomaly of the urinary tract with an incidence approaching 1 per cent. In one third of the cases it is complete, and both ureters enter the bladder separately. ${ }^{1}$ The most common pathologic condition associated with duplication is hydronephrosis. ${ }^{2}$ The syndrome of advanced segmental hydronephrosis masquerading as a renal neoplasm in adults is well recognized. Involvement of the upper segment is described most frequently and is often associated with an ectopic ureter or ureterocele. ${ }^{3-6}$ The impaired excretion of contrast material makes correct diagnosis by intravenous pyelography difficult. Delayed filming, nephrotomography, antegrade or retrograde pyelography, and renal angiography may be needed to define the lesion further; ${ }^{7}$ surgical exploration may ultimately be necessary.

Lower pole hydronephrosis has received little attention in the literature and is not usually considered in the differential diagnosis of renal masses. ${ }^{8}$ The lesion is surprisingly common, however, occurring with nearly twice the frequency of upper pole hydronephrosis. ${ }^{2}$ Vesicoureteral reflux is more common than obstruction in causing lower segment hydronephrosis. In fact, after excluding calculous obstruction (which occurs with equal frequency in upper and lower pole hydronephrosis), Goyanna and Greene ${ }^{2}$ found no evidence of structural obstruction in any of their patients with hydronephrosis of the lower pole. A short intravesical segment is said to predispose the lower pole duplicated ureter to reflux. ${ }^{9} \mathrm{De}$ pending on the presence of associated lower tract pathology and infection, reflux produces a characteristic spectrum of pyelographic findings that combines collecting system dilatation with parenchymal atrophy. Rarely, the misdiagnosis of renal tumor may occur secondary to reflux with parenchymal scarring. ${ }^{10,11}$ In the absence of obstruction, however, excretory function is usually preserved to a degree necessary to permit correct pyelographic diagnosis.

In the present case, nonobstructive hydronephrosis associated with reflux into a duplicated lower pole ureter has simulated a renal mass. The synergism between vesical outlet obstruction, infection, and neurogenic bladder dysfunction was no doubt responsible for the exaggerated parenchymal distortion and impaired excretory function. Appropriate therapy directed toward lower tract pathology has eliminated infection and has improved the cystographic appearance.

C5534 Outpatient Building University Hospital

Ann Arbor, Michigan 48104

\section{References}

1. Campbell, M. F., and Harrison, J. H.: Urology, 3rd ed., Philadelphia, W. B. Saunders Co., 1970, vol. 2, p. 1488.

2. Goyanna, R., and Greene, L. F.: The pathological and anomolous conditions associated with duplication of the renal pelvis and ureter, J. Urol. 54: 1 (1945).

3. Bosniak, M. A., Scheff, S, and Kaufman, S.: Localized hydronephrosis masquerading as renal neoplasm, ibid. 99: 241 (1968).

4. Koehler, P. R., and McAlister, W. H.: Nonopacified duplicated collecting systems simulating renal tumors in adults, J. Can. Assoc. Radiol. 19: 4 (1968).

5. Gross, M., and ChaIt, A.: Renal duplication with hydronephrotic segment, Am. J. Roentgenol. Radium Ther. Nucl. Med. 101: 728 (1967).

6. AmaR, A. D.: Reflux in duplicated ureters, Br. J. Urol. 40: 385 (1968).

7. Siegelman, S. S., and Bosniak, M. A.: Renal arteriography in hydronephrosis, Radiology 85: 609 (1965).

8. MARX, W. J., and PATEL, S. K.: Advanced, localized, lower pole hydronephrosis: a case report, J. Urol. 111: 563 (1974).

9. Ambrose, S. S., and Nicholson, W. P.: Ureteral reflux in duplicated ureters, ibid. 92: 439 (1964).

10. Kelalis, P. P.: Proper perspective on vesicoureteral reflux, Mayo Clin. Proc. 46: 807 (1971).

11. Weiss, R. M., and SCHIFF, M., JR.: Vesicoureteral reflux simulating renal mass lesions, Urology 4: 389 (1974). 